\title{
The North Atlantic variability structure, storm tracks, and precipitation depending on the polar vortex strength
}

\author{
K. Walter ${ }^{1}$ and H.-F. Graf ${ }^{1,2}$ \\ ${ }^{1}$ Max-Planck-Institute for Meteorology, Bundesstrasse 54, D-20146 Hamburg, Germany \\ ${ }^{2}$ Centre for Atmospheric Science, University of Cambridge, Dept. Geography, Cambridge, CB2 3EN, UK
}

Received: 10 June 2004 - Published in Atmos. Chem. Phys. Discuss.: 5 October 2004

Revised: 7 December 2004 - Accepted: 27 January 2005 - Published: 1 February 2005

\begin{abstract}
Motivated by the strong evidence that the state of the northern hemisphere vortex in boreal winter influences tropospheric variability, teleconnection patterns over the North Atlantic are defined separately for winter episodes where the zonal wind at $50 \mathrm{hPa}$ and $65^{\circ} \mathrm{N}$ is above or below the critical velocity for vertical propagation of zonal planetary wave 1 . We argue that the teleconnection structure in the middle and upper troposphere differs considerably between the two regimes of the polar vortex, while this is not the case at sea level. If the polar vortex is strong, there exists one meridional dipole structure of geopotential height in the upper and middle troposphere, which is situated in the central North Atlantic. If the polar vortex is weak, there exist two such dipoles, one over the western and one over the eastern North Atlantic. Storm tracks (and precipitation related with these) are determined by mid and upper tropospheric conditions and we find significant differences of these parameters between the stratospheric regimes. For the strong polar vortex regime, in case of a negative upper tropospheric "NAO" index we find a blocking height situation over the Northeast Atlantic and the strongest storm track of all. It is reaching far north into the Arctic Ocean and has a secondary maximum over the Denmark Strait. Such storm track is not found in composites based on a classic NAO defined by surface pressure differences between the Icelandic Low and the Azores High. Our results suggest that it is important to include the state of the polar vortex strength in any study of the variability over the North Atlantic.
\end{abstract}

Correspondence to: H.-F. Graf

(hfg21@cam.ac.uk)

\section{Introduction}

During boreal winter the climate in large parts of the Northern Hemisphere is under the influence of the North Atlantic Oscillation (NAO). The latter constitutes the dominant mode of tropospheric variability in the North Atlantic region including the North American East Coast and Europe, with extensions to Siberia and the Eastern Mediterranean. The NAO is characterised by a meridional oscillation of mass between two major centres of action over the subtropical Atlantic and near Iceland: the Azores High and the Iceland Low. Several studies suggest that the NAO is closely associated with the strength and direction of the North Atlantic storm tracks as well as with precipitation and temperature over Europe (Rogers, 1990; Hurrell, 1995; Hurrell and van Loon, 1997, among others). The difference of normalized sea level pressures between the Azores High and Iceland Low is often used to construct index time series of the NAO (Walker and Bliss, 1932; Hurrell, 1995). During winter months with a positive NAO index, i.e. with an enhanced north-south pressure gradient over the north Atlantic, northern Europe is in general characterized by warm and wet conditions and southern Europe (and in particular the Iberian Peninsula) by dry conditions. The opposite holds for months with a negative NAO index. However, Rogers (1997) stated that one of the two polarities of the leading mode of North Atlantic storm track variability corresponds to a blocking situation over the Northeast Atlantic with a strong northeastward tilt of the storm track axis and reduced precipitation over West Europe. This situation is not captured by standard NAO indices.

The typical time scale of the NAO is on the order of two weeks (Feldstein, 2003), but there are clearly much longer periods involved when the NAO tends to prefer one polarity. During the last decade these monthly, seasonal and even decadal NAO fluctuations were intensively studied concerning their connection to the upper boundary, the stratospheric polar vortex (Baldwin et al., 1994; Perlwitz and Graf, 1995;

(C) 2005 Author(s). This work is licensed under a Creative Commons License. 
and many others). The stratospheric polar vortex is primarily driven by radiative cooling during the polar night and can be disturbed by tropospheric planetary waves entering the stratosphere. In linear theory the probability for such waves propagating upward to higher atmospheric layers depends on the zonal wind speed and the vertical structure of the atmosphere as well as on the latitude and zonal wave number (Charney and Drazin, 1961). Under normal conditions in winter, only ultra long planetary waves can propagate into the stratosphere. This leads to much less variability, fewer degrees of freedom and longer time scales in the stratosphere than in the troposphere (Perlwitz and Graf, 2001). Feedbacks between the vortex strength and wave disturbances can lead to the formation of "regimes" of the stratospheric circulation - characterized by either a strong or a weak polar vortex (Hu and Tung, 2002). These natural regimes were found by Christiansen (2003) and by Perlwitz and Graf (2001) in observed data.

Baldwin and Dunkerton (2001) reported changes in the probability distribution function of the NAO index depending on the polarity of the stratospheric circulation regime: When the polar vortex is strong, the NAO index tends to be positive. They claimed that the build-up of either a strong or weak polar vortex in winter might he a harbinger for tropospheric climate related to the NAO. Perlwitz and Graf (2001) documented an impact of the troposphere on the lower stratosphere under any circumstances in winter, whereas the stratosphere acts back on the troposphere only if the polar vortex is strong. Castanheira and Graf (2003) were able to demonstrate that tropospheric variability structures are different for different stratospheric regimes. Namely a negative correlation between the Icelandic and the Aleutian Lows (Honda et al., 2002) exists only when the polar vortex is strong.

The processes responsible for coupling the stratospheric and the tropospheric circulation are still under discussion. Castanheira et al. (2002) showed that NAO and stratospheric polar vortex constitute two different Normal Modes of the atmosphere. A shift in atmospheric mass between subtropics and polar latitudes occurs when stratospheric regimes change polarity (Castanheira and Graf, 2003) and the pattern of this shift is very much like the pattern of the Arctic Oscillation as described by Thompson and Wallace (1998). Such shifts of the stratospheric circulation regimes can be forced externally, e.g. by volcanic eruptions in the tropics (Graf et al., 1994), by higher greenhouse gas concentration (Shindell et al., 1999) or, in late winter and spring, by loss of stratospheric ozone (Ramaswamy et al., 1996; Graf et al., 1998). But also internal dynamical processes can lead to changes of the stratospheric polar vortex (Matsuno, 1970). Waves generated in the troposphere play a dominant role, which can even lead to the breakdown of the vortex.

While the processes influencing the strength of the stratospheric polar vortex are quite well understood from modelling studies and observations, the dynamical reasons for the downward propagation of such signals are not. One ex- planation (Hines, 1974) is based on linear theory and suggests that the zonal winds in the stratosphere influence the refractive index and, thus, the propagation/refraction properties of planetary waves and their interaction with the mean flow (Charney and Drazin, 1961; Matsuno, 1970; Andrews et al., 1987). Limpasuvan and Hartmann (2000) and Hu and Tung (2002) found that such reflection takes place near the tropopause rather than in the lower stratosphere. This process may be strongest where the planetary waves are most pronounced, i.e. in the middle and high, but not in the polar latitudes. Hartley et al. (1998), Ambaum and Hoskins (2002) and Black (2002) suggested another mechanism. It is based on the fact that large-scale anomalies of potential vorticity in the lower stratosphere induce geopotential height anomalies in the polar troposphere through hydrostatic and geostrophic adjustment of the atmospheric column. A strong vortex in the lower stratosphere is then associated with anomalously low pressure in the troposphere near the pole. This represents a large scale annular "stirring" of the troposphere from above.

In the current paper we extend the work of Castanheira and Graf (2003) and investigate if the state of the stratospheric circulation also has an influence on the variability structure of the NAO. For this purpose we will first redefine the atmospheric teleconnectivity over the North Atlantic Ocean. We will do this for the upper troposphere rather than for the surface pressure, which is normally used for the definition of NAO indices. The reason is that the biggest differences in geopotential height and zonal winds are found in the upper troposphere when the data are separated into strong and weak polar vortex regimes (Christiansen, 2003). It turns out that in fact teleconnectivity is most different in the upper troposphere between the two stratospheric regimes. In a second step we will then, based on the newly defined indices for the North Atlantic teleconnections, study the differences in storm tracks and precipitation over the North Atlantic and Europe.

We used reanalysis data of geopotential height, air temperature, wind and precipitation from the National Centres for Environmental Prediction/National Centre for Atmospheric Research (NCEP/NCAR; Kalnay et al., 1996) for the winter months December to March from 1958 to 1998. The annual cycle was removed from the data prior to performing the analyses. Since the data are not completely homogeneous due to changes in the density and quality of observational input (e.g. the introduction of satellite information in 1979) we did not study trends, which were removed by subtracting ten year running means from the data. The results presented in the following, however, are not very different if the trends were included. The problems with data homogeneity are most evident in the tropics and over the Southern Hemisphere. Thus, we constrained our analyses to the Northern Hemisphere extra-tropics. Reanalysis data in the Northern Hemisphere extra-tropics are fairly accurate (Kistler et al., 2001). Rainfall estimates have limited reliability, particularly for convective rain, but in winter large-scale anomalies 
may be considered accurate to first order (Reid et al., 2001).

The zonal mean zonal wind at $65^{\circ} \mathrm{N}$ in $50 \mathrm{hPa}$ proved to be a good indicator of the strength of the polar vortex and was used to define stratospheric polar vortex regimes by Castanheira and Graf (2003). We adopted their thresholds of $>20 \mathrm{~m} / \mathrm{s}$ for the strong and $<10 \mathrm{~m} / \mathrm{s}$ for the weak polar vortex regime and defined 71 months as SVR and 32 months as WVR. The stratification of the polar vortex regimes is based on monthly anomalies, which reflect the time scale of stratospheric variability of several weeks (Baldwin and Dunkerton, 2001) rather than the tropospheric NAO time scale of two weeks (Feldstein, 2003).Upper tropospheric teleconnections are based on filtered daily data to capture the time scale of tropospheric variability. Climate anomalies like storm tracks and precipitation are analyzed on the basis of monthly means of the teleconnection indices.

\section{Results and discussion}

\subsection{Teleconnectivity}

Wallace and Gutzler (1981) introduced teleconnectivity as a search variable for teleconnections. For a given grid point, the correlations of a variable with all other grid points in a field are computed and the teleconnectivity for this grid point then is defined as the maximum negative correlation. The existence of real teleconnections has to be proved by the computation of correlation fields between the points of maximum teleconnectivity (centres of action) with the whole field. We performed a teleconnectivity analysis (Wallace and Gutzler, 1981) for the upper troposphere $(300 \mathrm{hPa}$ ) geopotential height fields separately for periods of strong (SVR) and weak (WVR) stratospheric polar vortex. Since remote teleconnections are characterized by low frequencies, the data has been low pass filtered with a Fourier filter removing fluctuations with periods shorter than 15 days.

Using all data (Fig. 1c), over the North Atlantic two large diffuse maxima of teleconnectivity extend zonally over almost the entire North Atlantic: One in the subpolar and the other over the subtropical latitudes. The maximum teleconnectivity is found between the western subtropical North Atlantic and northeastern Canada. The structures over the Pacific area constitute a wave train-like teleconnection pattern reaching from the (sub) tropical Pacific to the southeast coast of the USA, the Pacific/North American pattern (PNA). These will not be discussed any further in this paper since correlation analyses of geopotential height in their centres of actions revealed that the pattern structures are not profoundly different between the entire period, SVR, and WVR. This indicates that the PNA structure is not dependent on the state of the polar stratospheric vortex. However, the amplitude of PNA is correleted to the polar vortex strength (Castanheira et al., 2002).

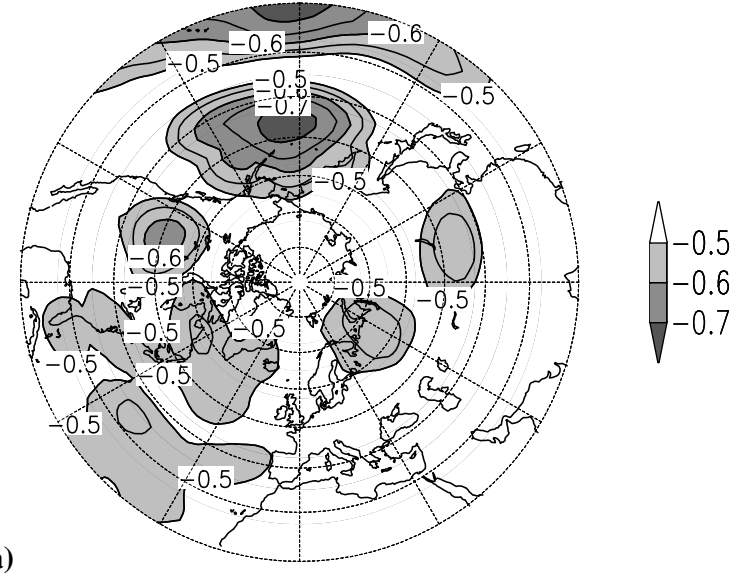

SVR

(b)

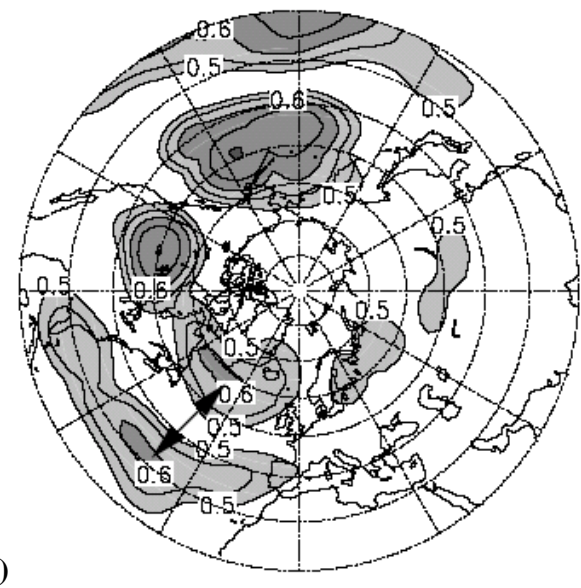

WVR

(c)

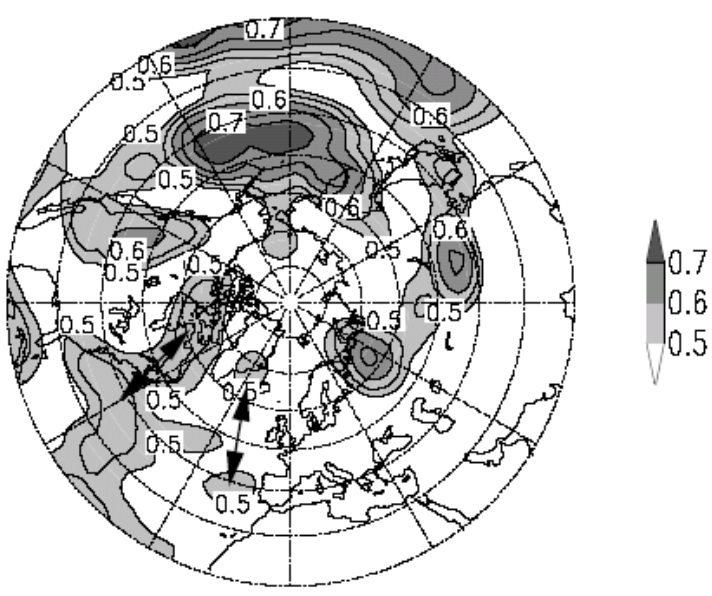

Fig. 1. Teleconnectivity of the 15-day low pass filtered geopotential height of the 300-hPa level in December to March from 1958 to 1998 . Isoline interval is 0.05 , only larger values than 0.5 are shown. (a) only periods with strong polar vortex, (b) only periods with weak polar vortex used, (c) all data. Arrows mark Atlantic centres of action of dominant teleconnection patterns in SVR and WVR. 

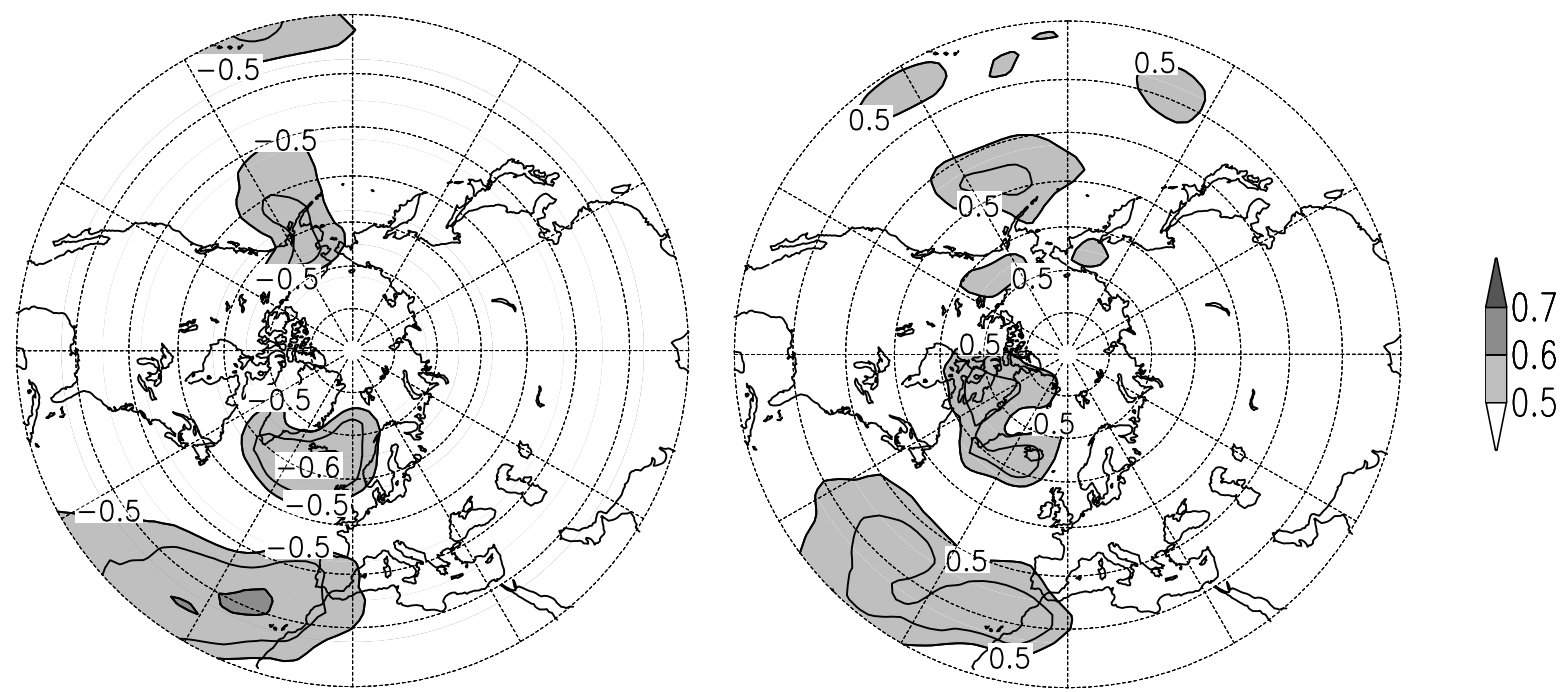

Fig. 2. As in Fig. 1, but for 15-day low pass filtered data at the $1000 \mathrm{hPa}$ level. The isoline interval is 0.05 . Only values larger than 0.5 are shown.

In the SVR, there are two zonally elongated areas of strong teleconnectivity over much of the North Atlantic (Fig. 1a). Their centres are located southeast of Greenland and in the subtropical central North Atlantic, respectively. Correlation maps of the geopotential height averaged over the two Atlantic teleconnectivity centres correlated with the geopotential height at each grid point revealed that we really diagnosed a dipole structured teleconnection pattern. This pattern will be referred to as the NA-SVR pattern in the following. Weak, but statistically significant anti-correlation between the Greenland centre and the Aleutian Low is found under SVR conditions in accordance with Castanheira and Graf (2003).

The associated pattern is reminiscent of a south-westwarddisplaced North Atlantic Oscillation pattern or of the combined "western" and "eastern Atlantic" patterns described by Wallace and Gutzler (1981). They derived their patterns for the 500-hPa heights and found the "eastern Atlantic" pattern about $5^{\circ} \mathrm{S}$ of our NA-SVR pattern.

While the NA-SVR pattern is thus characterized by a single teleconnection pattern over the central North Atlantic, there are two meridionally oriented dipole patterns in the WVR (Fig. 1b). The western pattern comprises centres of action over northeastern Canada and over the western part of the subtropical North Atlantic. The eastern pattern is found with centres of action northwest of Iceland/east of Greenland and just west of the Iberian Peninsula. Both patterns were proven to represent real teleconnection patterns by correlation analysis applied to the geopotential height field (not shown here), with the values at the centres of action taken as key values. They will be called western and eastern NAWVR patterns in the following. None of these centres of action is significantly correlated with the region of the Aleutian Low. This supports the argument of Castanheira and Graf (2003) that such correlation only appears under strong vortex conditions. The WVR patterns are characterized by a large number of March events, but the same patterns are obtained also when March is excluded. Hence, there is no seasonal effect included in the patterns. This also shows that the definitions of the regimes by fixed limits of zonal mean wind for the separation into regimes instead of statistically derived ones results in regimes that are physically based and stable. The vertical propagation characteristics of planetary waves are the same within one regime, independent of the season.

The teleconnection patterns described above do not differ much for different low pass filters: We also investigated 10and 20-day low pass filtered data and the results were similar. The only exception is that the western NA-WVR pattern is concealed by other teleconnection maxima in the 10-day low pass filtered data case. These teleconnection maxima vanish if higher frequencies are removed from the data set. For monthly mean data, the teleconnection patterns are also mainly similar to those presented in Fig. 1. In general, larger temporal smoothing increases teleconnection values. When monthly mean data are used, the eastern NA-WVR pattern is particularly prominent, both centres have values above 0.8 .

While the teleconnection patterns for the $500 \mathrm{hPa}$ geopotential height (not shown) are almost identical with those at $300 \mathrm{hPa}$, the situation is different in the lower troposphere (Fig. 2). Teleconnections are much weaker and all centres of action are located further to the east than in the upper troposphere. In the WVR there are imprints of the western NAWVR pattern with centres over Baffin Bay/northeast Canada 

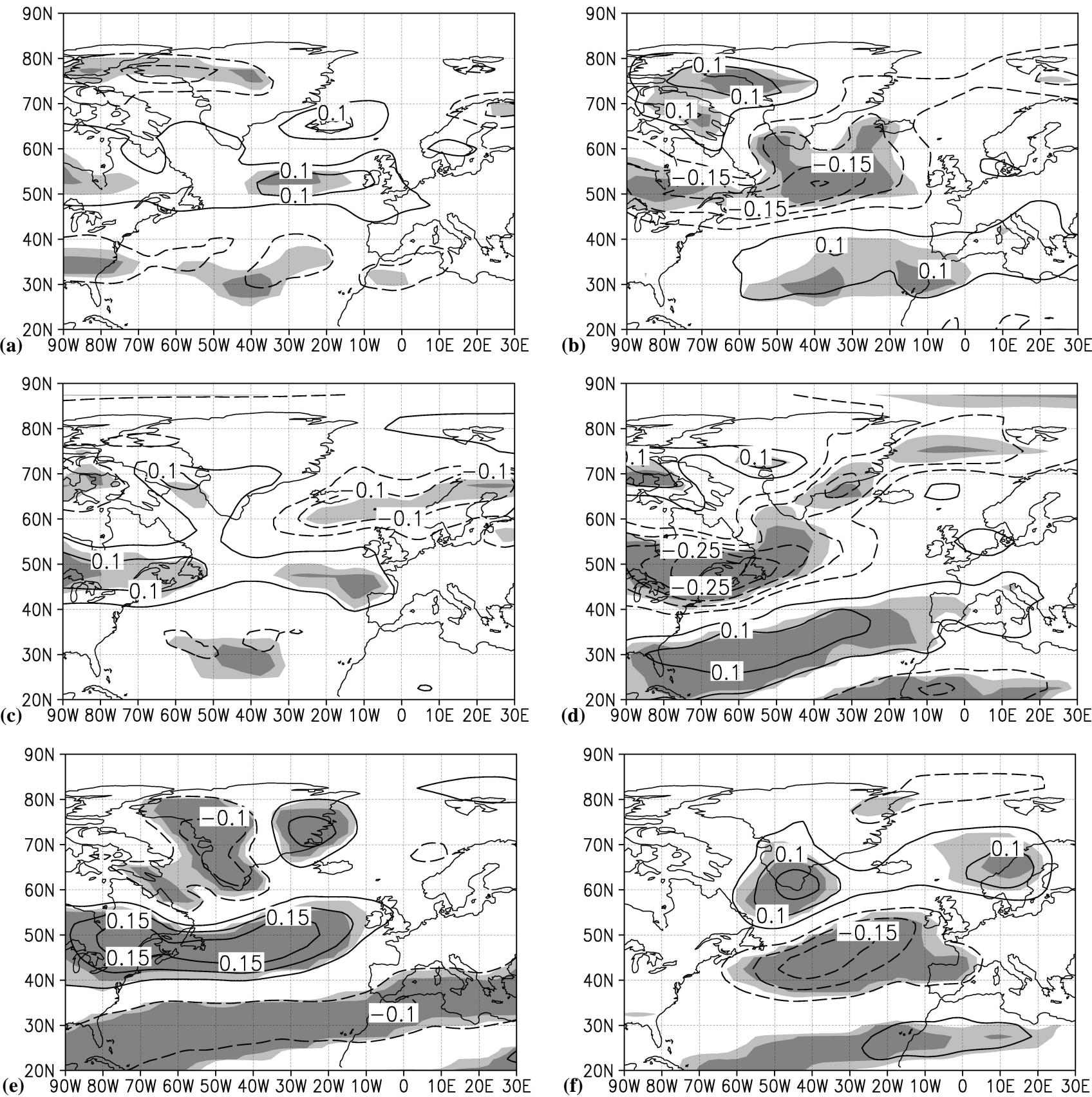

Fig. 3. Composites of the Eady growth rate (anomaly from 1958-1998 mean) for the positive (left) and negative (right) phase of the index of eastern NA-WVR pattern (a), (b), western NA-WVR pattern (c), (d), and SVR pattern (e), (f). Shadings indicate deviations from the time mean above the 95 (99) significance level (light (dark)).

and over the central North Atlantic. The structures of the eastern NA-WVR and the NA-SVR patterns are difficult to distinguish in the lower troposphere. While the subtropical centres may be separated by approximately $10^{\circ}$ longitudes, the subpolar centres overlap.

These results show that it is worthwhile to study North Atlantic teleconnections in the upper troposphere rather than near the surface if one wants to examine their connection to the state of the wintertime stratospheric circulation. Monthly means are a good trade-off between the strength of the teleconnections and detail of information in the retrieved climate anomaly patterns. However, it will not be sufficient for studies concerning the dynamic background of these. In the following we will investigate moonthly mean storm tracks 
and precipitation anomalies separately for the above defined teleconnection patterns under the two stratospheric circulation regimes (SVR and WVR). Due to the double selection process (stratospheric regime and phase of the index) the samples become relatively small, and so the only reasonable method is composite analysis together with $t$-test analysis to estimate the statistical significance of the anomalies.

\subsection{Index time series}

Index time series were constructed for the eastern $\left(65^{\circ}-\right.$ $70^{\circ} \mathrm{N}, 27.5^{\circ}-35^{\circ} \mathrm{W}$ and $\left.37.5^{\circ}-40^{\circ} \mathrm{N}, 15^{\circ}-22.5^{\circ} \mathrm{W}\right)$ and western $\left(62.5^{\circ}-65^{\circ} \mathrm{N}, 77.5^{\circ}-82.5^{\circ} \mathrm{W}\right.$ and $35^{\circ}-37.5^{\circ} \mathrm{N}$, $\left.55^{\circ}-62.5^{\circ} \mathrm{W}\right)$ NA-WVR patterns, and for NA-SVR $\left(55^{\circ}-\right.$ $60^{\circ} \mathrm{N}, 30^{\circ}-45^{\circ} \mathrm{W}$ and $30^{\circ}-35^{\circ} \mathrm{N}, 35^{\circ}-45^{\circ} \mathrm{W}$ ) using the difference of normalized geopotential height anomalies at the southern and northern centres of action of the respective teleconnection pattern. A positive index then stands for an enhanced north-south geopotential height gradient. The definition corresponds to a commonly used version of the NAO index based on the difference between normalized sea level pressures at the Azores and Iceland (Hurrell, 1995).

The monthly mean eastern NA-WVR pattern index is highly correlated (0.91) with a "classic" NAO index based on sea level pressure over Iceland and the Azores, while the western NA-WVR index (0.62) and the NA-SVR (0.74) index are much less, although still significantly, correlated with the NAO index. The correlation between the eastern and western NA-WVR monthly mean indices is 0.41 . This is a result of spatial overlapping of the patterns and of temporal averaging. Eastern and western NA-WVR indices are only very weakly correlated based on 15-day (the time scale of the NAO life cycle) low pass filtered data (0.18), but the correlation increases to 0.37 if the eastern index leads the western by approximately 4 days. This may give rise to the speculation that there might be an upstream connection between the two patterns. This phenomenon shall be discussed in a later study. Only the western NA-WVR pattern index is significantly correlated $(0.68)$ with the strength of the polar vortex when the polar vortex is leading by 1-2 days (based on 10 and 15 day low pass filtered data). The eastern NA-WVR pattern index and the NA-SVR index are only marginally correlated to the strength of the polar vortex. This means that, within the limits of the polar vortex regimes, only the western NA-WVR pattern reacts to changes in the polar vortex strength, very probably to changes in the vertical wind profile (see discussion of Eady growth rate below).

\subsection{Storm tracks and precipitation}

In order to examine the effects of stratospheric regimes on storm tracks and precipitation in the North Atlantic area we applied composite analysis. The composites were averaged over all months in which the monthly mean time series of the corresponding teleconnection index was above (below)
$+(-) 0.5$ standard deviation. The strength and direction of the storm tracks is represented by the monthly root mean square of band pass filtered 500-hPa geopotential heights. The data were band pass filtered using the filter of Blackmon and Lau (1980) capturing fluctuations between 2.5 and 6 days. Monthly mean precipitation rates and Eady growth rates (Fig. 3) were considered as anomalies from the average over the entire period from 1958 to 1998 . The "Eady" growth rate of the most unstable wave in the Eady model (Eady, 1949; see also James, 1994) is a measure for the baroclinic production of transient eddies. It depends on the static stability and on vertical wind shear and is calculated for the lower troposphere $(700 \mathrm{hPa})$. The vertical derivatives were approximated by centred differences between the $500 \mathrm{hPa}$ and $925 \mathrm{hPa}$ levels. We will use this parameter for the interpretation of the storm track anomalies.

Figure 4 shows composites for the eastern NA-WVR pattern index, which consist of 11 (10) months in the positive (negative) index case. In the positive index phase, the North Atlantic storm track is more zonally elongated (Fig. 4a) than in the negative phases (Fig. 4b) and has a stronger southwest to northeast tilt. The area with standard deviations above $40 \mathrm{gpm}$ reaches the Greenwich meridian, whereas it only reaches $30^{\circ} \mathrm{W}$ in the negative index case. In the positive index case, cyclones are led to northwestern Europe bringing more precipitation to this area and less precipitation to the Iberian Peninsula (Fig. 4c). The situation is vice versa in the negative index phase (Fig. 4d). This result perfectly matches the results of "classic" NAO studies (see e.g. Rogers, 1997 and in Hurrel et al., 2003). This is in accordance with the very high correlation between eastern NA-WVR and surface NAO indices. Anomalies in the WVR are larger in the negative index phase because they are calculated against the total mean 1958-1998 and during WVR the NAO has a negative bias.

The elongation of the storm track in the positive index phase can be explained by the stronger upper level easterly wind of the anomalous low near Iceland. This is connected to a larger Eady growth rate and, hence, stronger baroclinicity in this area. Positive (negative) wind anomalies are located north of the jet core and negative (positive) anomalies are found to the south of it. Therefore, the area of strongest baroclinicity over the North American East Coast is displaced north (south) in the positive (negative) index case. This is associated with northward (southward) shift of the storm track axis.

The composites for the western NA-WVR also consist of 11 (10) months (Fig. 5). The storm tracks show a similar qualitative behaviour with the polarity of the index as for eastern NA-WVR. In the positive phase the storm track is longer and stronger than in the negative phase. This difference is more pronounced than in the eastern NA-WVR case. This may be explained by the strong anomalies of the upper tropospheric westerly wind over the western North Atlantic and America. Consequently, fluctuations in the western NA- 


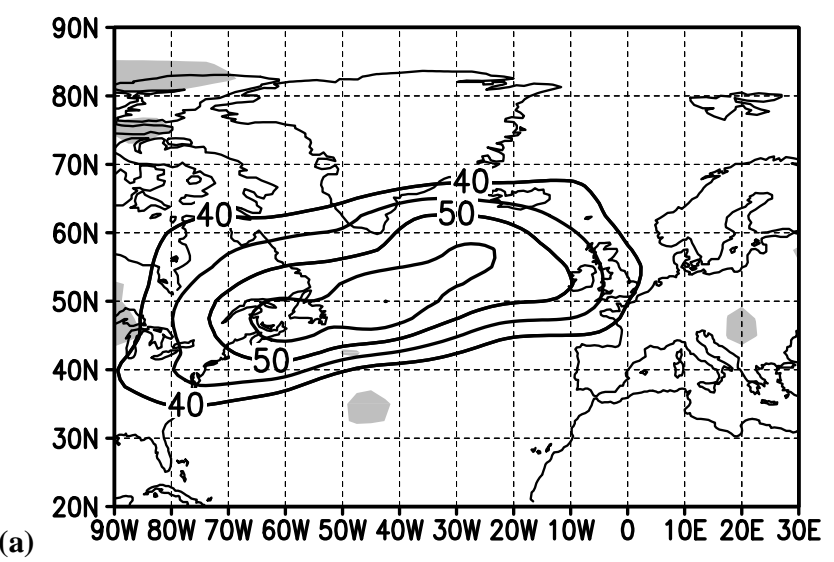

(a)

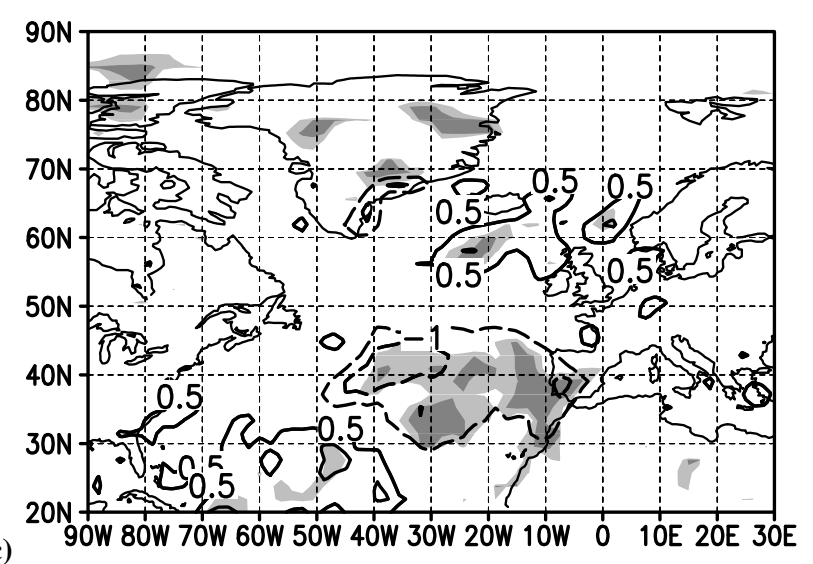

(b)
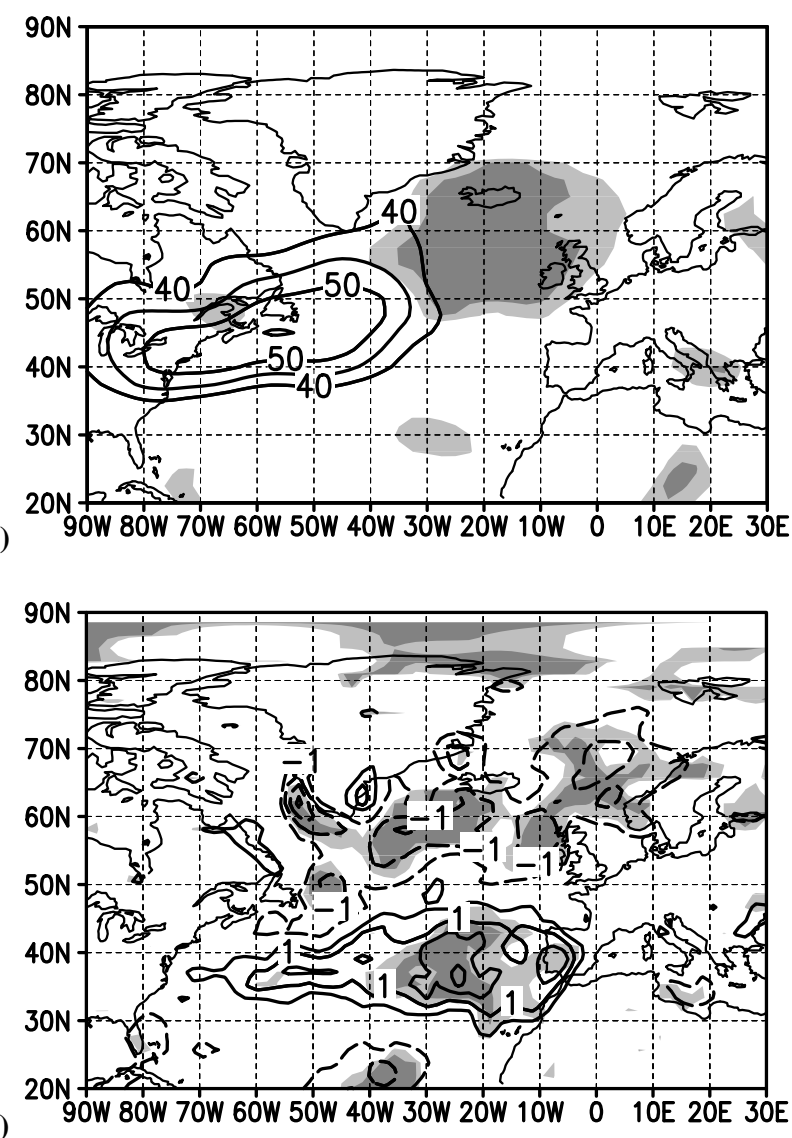

Fig. 4. Composites of the positive (left) and negative (right) of the index of eastern NA-WVR pattern: (a), (b) monthly rms of bandpass filtered $500 \mathrm{hPa}$ geopotential height, (c), (d) precipitation rate $(\mathrm{mm} / \mathrm{d})$. Anomalies are deviations from 1958-1998 time mean. Shadings indicate deviations from the time mean above the 95 (99) significance level (light (dark)).

WVR pattern strongly modify the baroclinicity over the East Coast of North America, i.e. in a region, which is already characterized by strong synoptic eddy growth due to baroclinic instability. In the positive phase, the position of the strongest baroclinicity is displaced northward, leading to a similar displacement of the storm track axis. The area of (weakly) enhanced precipitation is located further south than in the positive eastern NA-WVR index case, i.e. it is situated over western to southern Europe, while the precipitation at the Norwegian coast is weakly, but significantly, reduced. The anomaly pattern of the negative phase of the western NA-WVR index resembles the negative eastern NA-WVR case - apart from the fact that the maxima and minima are shifted to the west and that the effects over the continents are smaller.

The behaviour of storm tracks and precipitation in the SVR is much different from that in WVR. Figure 6 shows the composites for the NA-SVR pattern in the strong vortex regime, which consists of 26 (24) monthly values in the positive (negative) index case. For both polarities of the telecon- nection index, the storm tracks span the entire North Atlantic Ocean. This corresponds to the fact that the time mean westerly flow in the midlatitude North Atlantic region is stronger in the SVR than in the WVR (e.g. Castanheira and Graf, 2003). The storm track is extremely tilted in the negative index case (Fig. 6b) when an (blocking) anticyclone southeast of Iceland is associated with enhancement of the westerly flow to its north and reduction south of it.

The storm track axis runs from the southwest to the northeast over the Denmark Strait and north of Iceland. Cyclones move along this path to the Norwegian coast and are responsible for enhanced precipitation in this region (Fig. 6d). Although small in space, these precipitation rate anomalies are statistically highly significant (above the $99.9 \%$ level) and can be explained by orographic effects. Very important also are the strong positive precipitation anomalies at the southwest coast of Greenland that occur during the SVR negative index phase. These anomalies are due to the northerlydeflected storm tracks and may, together with the anomalies at the Norwegian coast, serve as a proxy for the strength of 

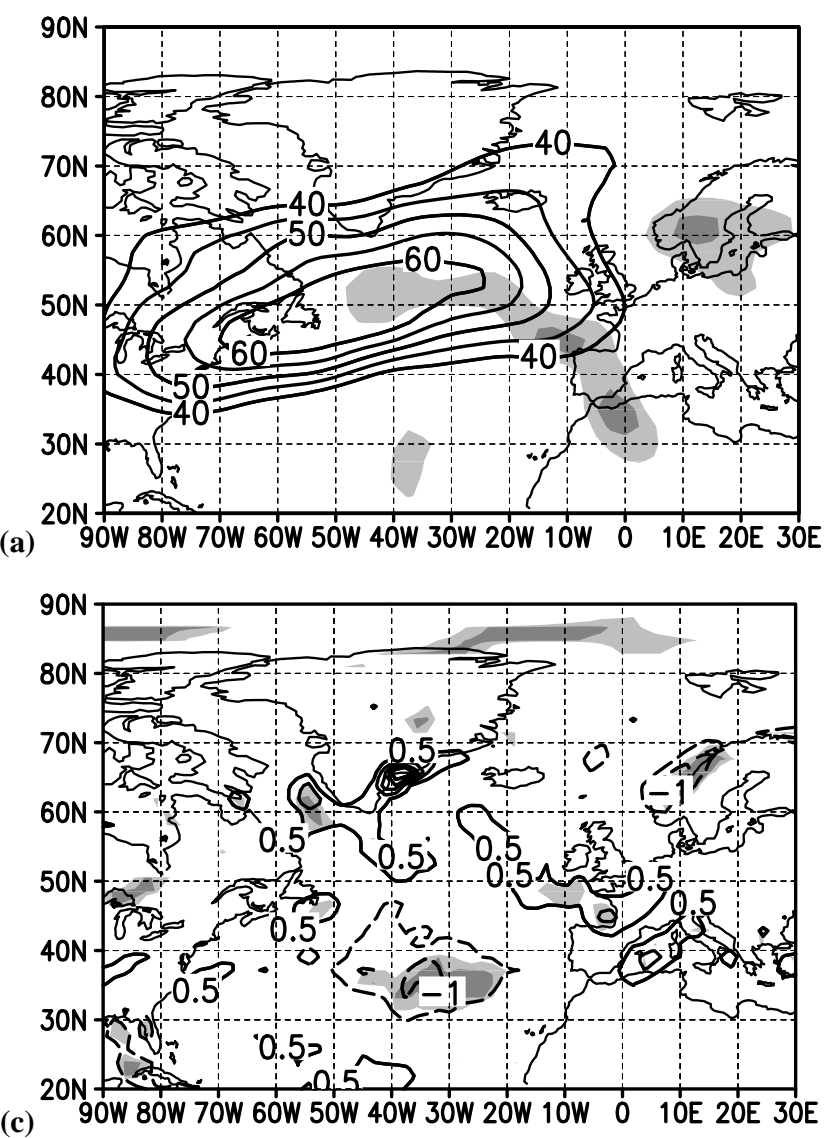

Fig. 5. As Fig. 4, but for western NA-WVR.

the polar vortex. The precipitation over the British Isles and Western Europe is reduced corresponding to the blocking situation. When the NA-SVR index is in its positive phase, the westerly wind south of the anomalously deep low near Iceland is enhanced. Therefore, the storm track is more zonally oriented (Fig. 6a). In the positive NA-SVR phase cyclones reach Europe more southerly than in the negative NA-SVR phase. This results in more precipitation over (north-) western, and less over southern Europe in the negative than in the positive phase - just the opposite of what would be expected from a standard NAO analysis.

\section{Conclusions}

Teleconnections of North Atlantic geopotential heights were examined separately for winter months (December to March) characterized by either a strong or a weak stratospheric polar vortex. In both cases, the major teleconnection patterns have north-south dipole structures with opposing centres of action in subpolar and subtropical latitudes. The middle to upper troposphere in the strong vortex regime (SVR) is characterized by a single teleconnection pattern over the central North

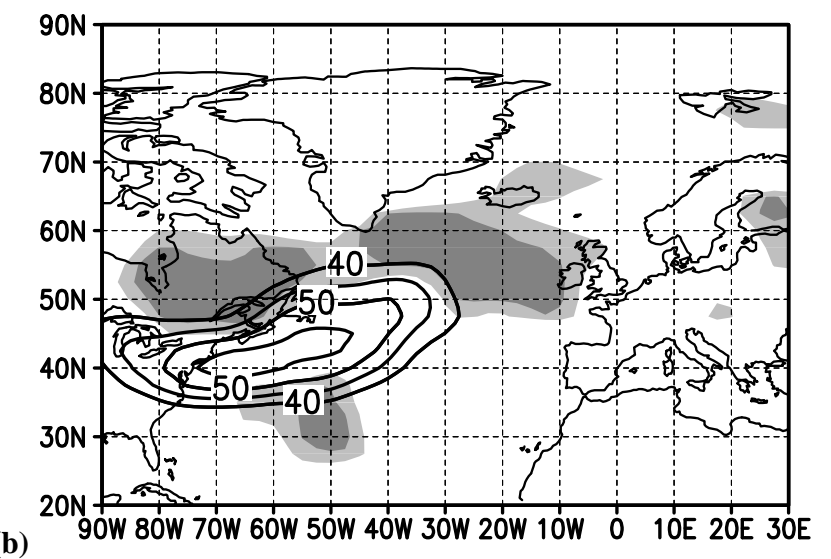

(b)

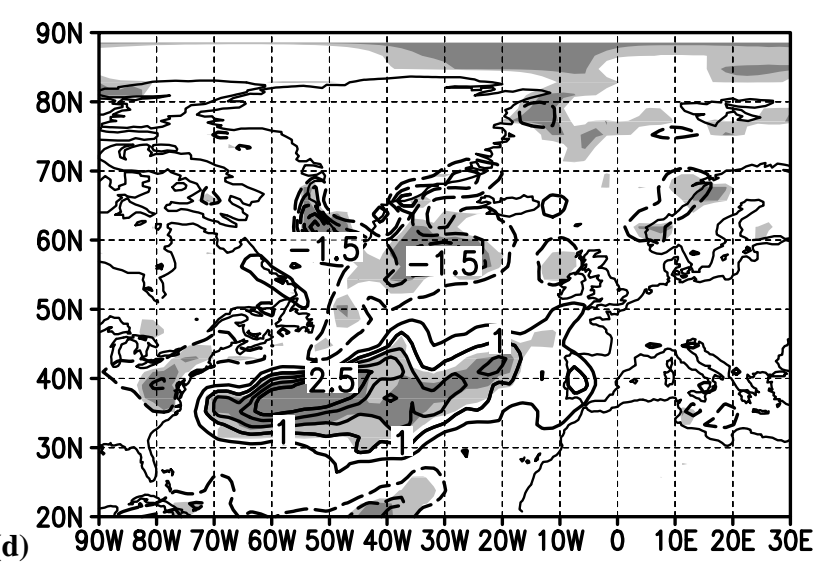

Atlantic with a basically dipolar structure, the NA-SVR pattern. In contrast, there are two dipole patterns in the weak polar vortex regime (WVR): One over north-eastern Canada and the western North Atlantic (western NA-WVR pattern) and one over the eastern North Atlantic (eastern NA-WVR pattern). In the lower troposphere, however, the NA-SVR and the eastern NA-WVR patterns are very similar, in particular concerning their northern centres of action.

The fluctuations in both, the North Atlantic storm track and the precipitation rates, show significant differences between the two polar vortex regimes. Composites of the winter North Atlantic storm track and precipitation rates for the two polarities of a "classic" NAO index (without considering the polar vortex regimes in the stratosphere) mainly correspond to the composites of the positive phase of the NA-SVR pattern index and the negative phase of the eastern NA-WVR pattern index, respectively.

The composites of the negative phase of the NA-SVR pattern index, however, describe a blocking situation (in the SVR low frequency energy is enhanced significantly over the central-east NA as compared with WVR (not shown here) over the North Atlantic with a very strong north-eastward 


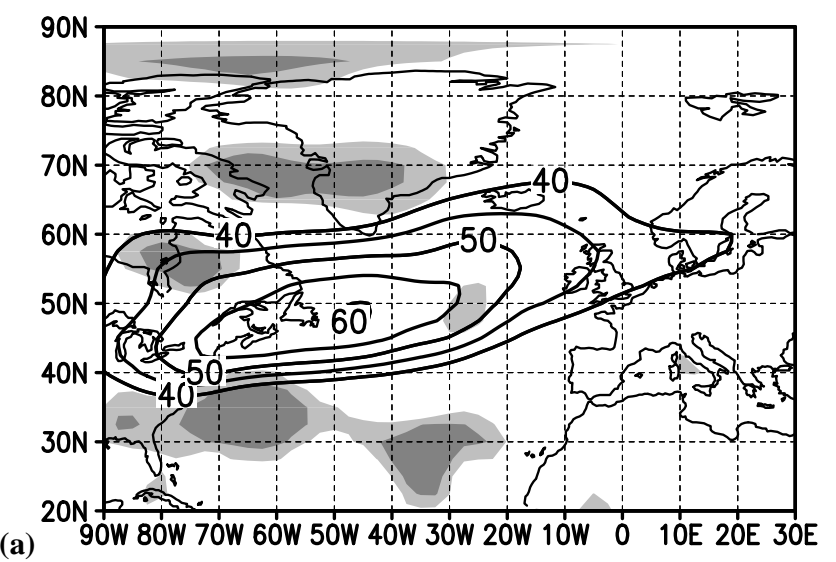

(a)

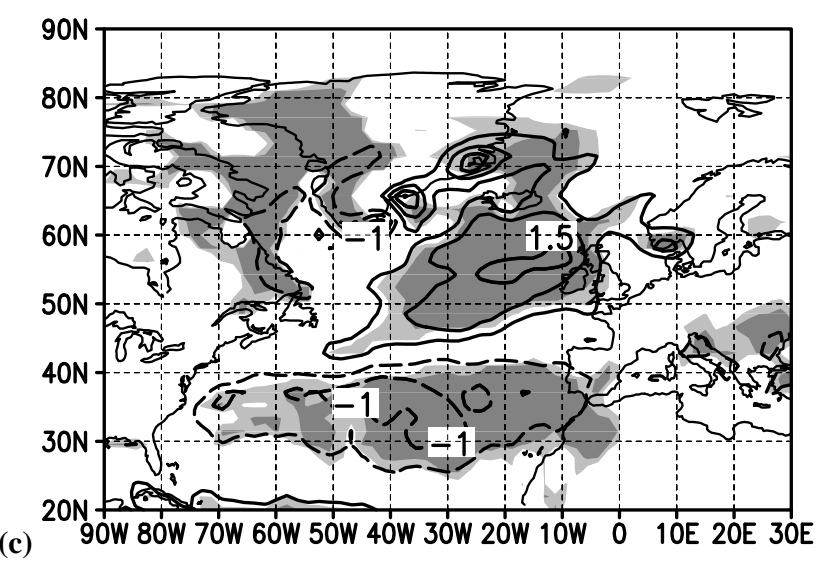

(b)
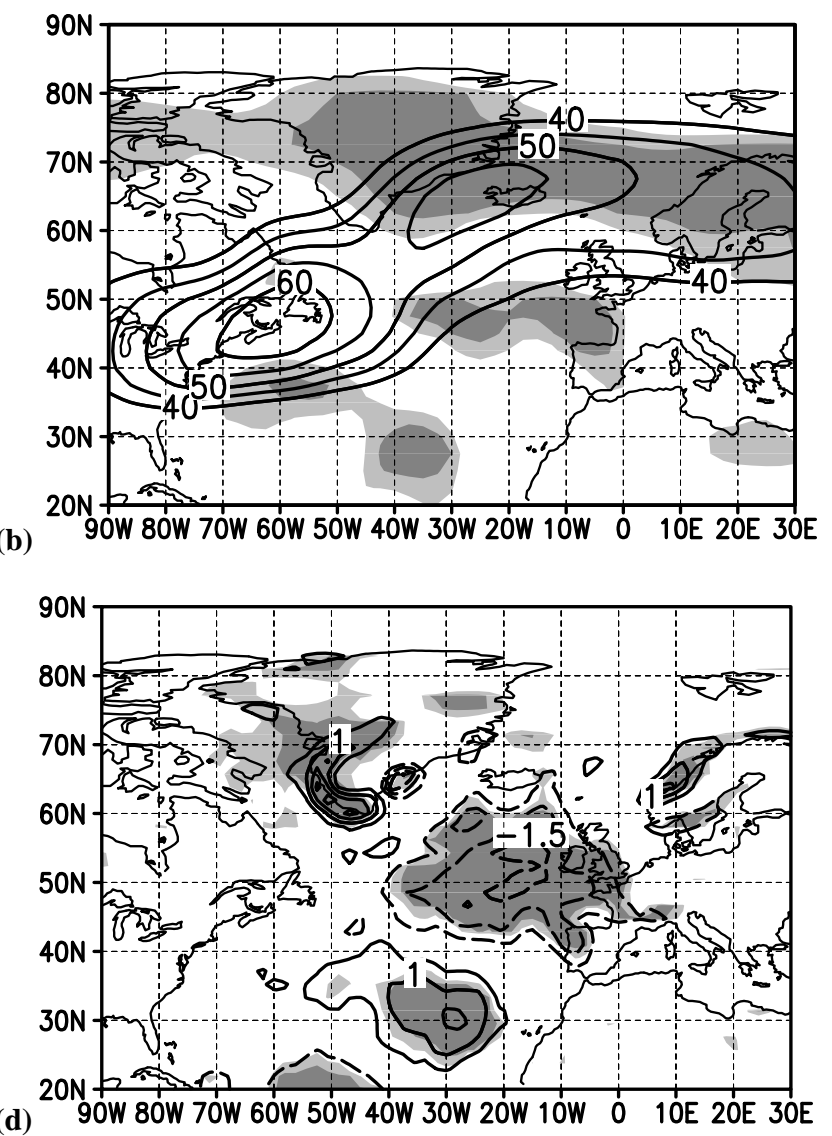

Fig. 6. As Fig. 4, but for SVR.

tilt of the storm track axis and reduced precipitation over Western Europe. This situation is consistent with results of Rogers (1997). He showed that one of the two polarities of the leading mode of the North Atlantic storm track variability corresponds to a blocking high situation, which is not captured by a classic NAO index composite. This emphasizes the need to consider the state of the polar vortex for describing the atmospheric variability in the North Atlantic region. While a classic NAO index may be appropriate for a statistical description of fluctuations in the lower troposphere (like the advection of warm and cold air masses leading to near surface temperature anomalies), it should not be used for examining processes in higher tropospheric layers - like the propagation of synoptic storms and the precipitation connected therewith. A substantial subset of variability will be missed if the dynamic processes in above-tropospheric layers associated with the strength of westerly winds in the polar vortex are not considered. Climate forecasts based on a forecast of the NAO and statistical downscaling of its effects would lead to wrong conclusions when the state of the stratosphere is not taken into account (Castanheira et al., 2002). The dynamical processes behind the results discussed in this paper will be investigated in a forthcoming paper based on an analysis of stream function divergence.
Acknowledgements. This work was supported by BMBF under the AFO2000 project KODYACS and by the European Commission FW5 Project PARTS.

Edited by: P. Haynes

\section{References}

Ambaum, M. H. P. and Hoskins, B. J.: The NAO tropospherestratosphere connection, J. Climate, 15, 1969-1978, 2002.

Andrews, D. G., Holton, J. R., and Leovy, C. B.: Middle Atmosphere Dynamics, Academic press, Orlando, 487, 1987.

Baldwin, M. P. and Dunkerton, T. J.: Propagation of the Arctic Oscillation from the stratosphere to the troposphere, J. Geophys. Res., 104, 30 937-30 946, 1999.

Baldwin, M. P. and Dunkerton, T. J.: Stratospheric harbingers of anomalous weather regimes, Science, 294, 581-584, 2001.

Baldwin, M. P., Cheng, X. H., and Dunkerton, T. J.: Observed relations between winter-mean tropospheric and stratospheric circulation anomalies, Geophys. Res. Lett., 21, 1141-1144, 1994.

Black, R. X.: Stratospheric forcing of surface climate in the Arctic Oscillation, J. Climate, 15, 268-277, 2002.

Blackmon, M. L. and Lau, N.-C.: Regional characteristics of the Northern Hemisphere wintertime circulation: A comparison of the simulation of a GFDL general circulation model with observations, J. Atmos. Sci., 37, 497-514, 1980. 
Castanheira, J. M., Graf, H.-F., DaCamara, C. C., and Rocha, A.: Using a physical reference framework to study global circulation variability, J. Atmos. Sci., 59, 1490-1501, 2002.

Castanheira, J. M. and Graf, H.-F.: North Pacific-North Atlantic relationships under stratospheric control?, J. Geophys. Res., 108, Art. No. 4036, doi:10.1029/2002JD002754, 2003.

Charney, J. G. and Drazin, P. G.: Propagation of planetary-scale disturbances from the lower into the upper atmosphere, J. Geophys. Res., 66, 83-109, 1961.

Christiansen, B.: Evidence for nonlinear climate change: Two stratospheric regimes and a regime shift, J. Climate, 16, 22, 3681-3690, doi:10.1175/15200442(2003)016<3681:EFNCCT>2.0.CO;2, 2003.

Eady, E. T.: Long waves and cyclone waves, Tellus, 1, 33-52, 1949.

Feldstein, S. B.: The dynamics of NAO teleconnection pattern growth and decay, Quart. J. Roy. Met. Soc., 129, 901-924, 2003.

Graf, H.-F., Perlwitz, J., and Kirchner, I.: Northern Hemisphere tropospheric mid-latitude circulation after violent volcanic eruptions, Contrib. Atmos. Phys., 67, 3-13, 1994.

Graf, H.-F., Kirchner, I., and Perlwitz, J.: Changing lower stratospheric circulation: The role of ozone and greenhouse gases, J. Geophys. Res., 103, 11 251-11 261, 1998.

Hartley, D. E., Villarin, J. T., Black, R. X., and Davies, C. A.: A new perspective on the dynamical link between the stratosphereand troposphere, Nature, 391, 471-474, 1998.

Hines, C. O.: A possible mechanism for the production of sunweather correlations, J. Atmos. Sci., 31, 589-591, 1974.

$\mathrm{Hu}$, Y. Y. and Tung, K. K.: Interannual and decadal variations of planetary wave activity, stratospheric cooling, and Northern Hemisphere Annular mode, J. Climate, 15, 1659-1673, 2002.

Hurrell, J. W.: Decadal trends in the North Atlantic Oscillation: Regional temperatures and precipitation, Science, 269, 676-679, 1995.

Hurrell, J. W. and van Loon, H.: Decadal variations in climate associated with the North Atlantic Oscillation, Clim. Change, 36, 301-326, 1997.

Hurrell, J. W., Kushnir, Y., Ottersen, G., and Visbek, M. (Eds): The North Atlantic Oscillation: Climate Significance and Environmental Impact, Geophysical Monograph Series, 134, 279 pp., 2003.

James, I. N.: Introduction to Circulating Atmospheres, Cambridge University press, Cambridge, 422 pp., 1994.

Kalnay, E., Kanamitsu, M., Kistler, R., Collins, W., Deaven, D., Gandin, L., Iredell, M., Saha, S., White, G., Woollen, J., Zhu, Y., Chelliah, M., Ebisuzaki, W., Higgins, W., Janowiak, J., Mo, K. C., Ropelewski, C., Wang, J., Leetmaa, A., Reynolds, R., Jenne, R., and Joseph, D.: The NCEP/NCAR 40-year reanalysis project, Bull. Amer. Meteor. Soc., 77, 437-472, 1996.
Kistler, R., Kalnay, E., Collins, W., Saha, S., White, G., Woollen, J., Chelliah, M., Ebisuzaki, W., Kanamitsu, M., Kousky, V., van den Dool, H., Jenne, R., and Fiorino, M.: The NCEP-NCAR 50-year reanalysis: Monthly means CD-ROM and documentation, Bull. Amer. Meteor. Soc., 82, 247-268, 2001.

Limpasuvan, V. and Hartmann, D. L.: Wave-maintained annular modes of climate variability, J. Climate, 13, 4414-4429, 2000.

Matsuno, T.: Vertical propagation of stationary planetary waves in the winter Northern Hemisphere, J. Atmos. Sci, 27, 871-883, 1970.

Perlwitz, J. and Graf, H.-F.: The statistical connection between tropospheric and stratospheric circulation of the Northern Hemisphere in winter, J. Climate, 8, 2281-2295, 1995.

Perlwitz, J. and Graf, H.-F.: The variability of the horizontal circulation in the troposphere and stratosphere: A comparison, Theor. Appl. Clim., 69, 149-161, 2001.

Perlwitz, J. and Harnik, N.: Observational evidence of a stratospheric influence on the troposphere by planetary wave reflection, J. Climate, 16, 3011-3026, 2003.

Ramaswamy, V., Schwarzkopf, M. D., and Randel, W. J.: Fingerprint of ozone depletion in the spatial and temporal pattern of recent lower-stratospheric cooling, Nature, 382, 616-618, 1996.

Raible, C. C., Luksch, U., Fraedrich, K., and Voss, R.: North Atlantic decadal regimes in a coupled GCM simulation, Clim. Dyn., 18, 321-330, 2001.

Reid, P. A., Jones, P. D., Brown, O., Goodess, C. M., and Davies, T. D.: Assessments of the reliability of NCEP circulation data and relationships with surface climate by direct comparisons with station based data, Clim. Res., 17, 247-261, 2001.

Rogers, J. C.: Patterns of low-frequency monthly sea-level pressure variability (1899-1986) and associated wave cyclone frequencies, J. Climate, 3, 1364-1379, 1990.

Rogers, J. C.: North Atlantic storm track variability and its association to the North Atlantic Oscillation and climate variability of Northern Europe, J. Climate, 10, 1635-1647, 1997.

Shindell, D. T., Miller, R. L., Schmidt, G. A., and Pandolfo, L.: Simulation of recent winter climate trends by greenhouse-gas forcing, Nature, 399, 452-455, 1999.

Thompson, D. W. J. and Wallace, J. M.: The Arctic Oscillation signature in the wintertime geopotential height and temperature fields, Geophys. Res. Lett., 25, 1297-1300, 1998.

Walker, G. T. and Bliss, E. W.: World weather V, Mem. Roy. Meteorol. Soc. 4, 53-84, 1932.

Wallace, J. M. and Gutzler, D. S.: Teleconnections in the geopotential height field during the Northern Hemisphere winter, Mon. Wea. Rev., 109, 784-812, 1981. 